\title{
Balancing the benefits and harms of oral anticoagulation in non-valvular atrial fibrillation
}

\section{SUMMARY}

Non-valvular atrial fibrillation is becoming more common in Australia and globally.

The direct oral anticoagulants apixaban, dabigatran and rivaroxaban offer an improved safety profile over warfarin.

Patient preferences are important and shared decision-making supports better adherence to treatment.

\section{Introduction}

The decision to start, continue or stop oral anticoagulation is common and challenging in patients with non-valvular atrial fibrillation. A disabling stroke is a disaster for the patient and their family, as is a disabling or fatal bleed.

\section{Increasing prevalence of atrial fibrillation}

The most common reason to prescribe anticoagulation is for thromboembolic prophylaxis in clinically diagnosed atrial fibrillation or paroxysmal atrial fibrillation. Unlike some risk factors for stroke (blood pressure, cholesterol, smoking), the prevalence and incidence of atrial fibrillation is increasing globally. This is possibly due to increasing obesity and an ageing population, including more people surviving with chronic heart disease.

In Australia, stroke physicians see many patients with large artery occlusion due to embolic stroke (perhaps up to $40 \%$ of ischaemic stroke). The majority of these patients are in atrial fibrillation but are not anticoagulated, emphasising the gap between evidence and practice. ${ }^{2,3}$

\section{Patient preferences}

To understand the factors that influence treatment success, it is important to know patient preferences. A recent systematic review ${ }^{4}$ found that patient preferences do not align well with anticoagulation guidelines, with perhaps only two-thirds of patients accepting guideline-recommended treatment. Patients are willing to accept the risks of bleeding to prevent stroke if this represents an absolute risk reduction of at least $1 \%$ per year. The review also found that physicians put more weight on bleeding risks, and patients put more weight on stroke reduction. Convenience was also an important factor for patients - including once a day treatment, no bridging requirement (intravenous heparin or subcutaneous low-molecularweight heparins), no food interactions and no need for monitoring. ${ }^{4}$ If these patient and physician preferences are considered, the direct oral anticoagulants (DOACs) such as apixaban, rivaroxaban and dabigatran can be seen as a useful advance. Shared decision-making is key and ensures that patients and their families are clear partners in the conversation. ${ }^{5}$

\section{Direct oral anticoagulants versus warfarin}

Trial evidence showing that DOACs were non-inferior (or superior) to warfarin for prevention of ischaemic stroke has been matched in routine clinical practice. ${ }^{6}$ They may also be associated with less discontinuation by patients (in the USA) compared to warfarin. However, discontinuation remains common with DOACs and warfarin, and this issue needs to be part of shared decision-making. . $^{5,7}$

A comparative meta-analysis found that DOACs have a lower risk of intracranial haemorrhage and a higher risk of gastrointestinal bleeding than warfarin. ${ }^{9}$ Given the changing evidence together with patient preferences, it is no surprise that since 2014 more people needing oral anticoagulation have been started on DOACs rather than warfarin in Australia. ${ }^{10}$

\section{Australian practice}

There is evidence of under- and over-treatment of those in atrial fibrillation - in many cases this is due to clinicians not following guidelines." These recommend that the decision to anticoagulate should be based on the sexless $\mathrm{CHA}_{2} \mathrm{DS}_{2}$-VA score
Richard I Lindley (D) Professor, Westmead Applied Research Centre, Faculty of Medicine and Health, University of Sydney George Institute for Global Health, Sydney

\section{Keywords}

anticoagulants, apixaban, atrial fibrillation, dabigatran, haemorrhage, rivaroxaban, thromboembolism

Aust Prescr 2020;44:49-52

https://doi.org/10.18773/ austprescr.2021.002 
(see Table). ${ }^{12}$ Approximately $75 \%$ of patients for whom oral anticoagulation is recommended $\left(\mathrm{CHA}_{2} \mathrm{DS}_{2}-\mathrm{VA}\right.$ score $\geq 2$ ) do not receive it and about a quarter of those who should not receive it (score of 0 ) do receive it." Given this large discrepancy between the evidence and clinical practice, it is important to review the current national guidelines. ${ }^{12,13}$

When oral anticoagulation is recommended, further assessment of the patient is required. This needs to take account of the patient's preferences and expectations, ${ }^{5}$ the presence of contraindications and whether any of these are modifiable. For example, if a patient has troublesome haemorrhoids that bleed, treating them (e.g. by injection or surgery) could allow safer oral anticoagulation in the future. Other potentially modifiable factors include falls, alcohol intake, uncontrolled hypertension and other medicines such as non-steroidal anti-inflammatory drugs and antiplatelet drugs.

\section{Bleeding risk}

When weighing up the risks and benefits of anticoagulation, it is useful to consider the following:

- the main types of serious bleeding - intracranial and gastrointestinal

- important patient factors - renal failure, older age, concomitant antiplatelet therapy.

Risk scores have been developed to predict bleeding in patients on anticoagulants. Unfortunately, these have not been as clinically useful as hoped because the likelihood of stroke and the likelihood of bleeding

\section{Table Definition and scoring of $\mathrm{CHA}_{2} \mathrm{DS}_{2}$-VA to guide oral} anticoagulant therapy in non-valvular atrial fibrillation

\begin{tabular}{|c|c|c|}
\hline Item & Definition & Points \\
\hline C & Heart failure & 1 \\
\hline H & Hypertension & 1 \\
\hline $\mathbf{A}_{2}$ & Age $\geq 75$ years old & 2 \\
\hline D & Diabetes & 1 \\
\hline $\mathbf{S}_{2}$ & History of stroke/transient ischaemic attack/systemic embolus & 2 \\
\hline V & $\begin{array}{l}\text { Vascular disease (myocardial infarction, peripheral vascular } \\
\text { disease or known complex atheroma) }\end{array}$ & 1 \\
\hline A & Age $65-74$ years & 1 \\
\hline \multicolumn{3}{|c|}{ Recommendations } \\
\hline \multicolumn{3}{|c|}{ Score = 0: oral anticoagulant or antiplatelet drugs not recommended } \\
\hline \multicolumn{3}{|c|}{ Score = 1: consider oral anticoagulants } \\
\hline Score & oral anticoagulants recommended & \\
\hline
\end{tabular}

Recommendations adapted from the National Heart Foundation of Australia and the Cardiac Society of Australia and New Zealand Clinical Guidelines ${ }^{12}$ both increase with risk factors such as age. However, the individual components of the score (such as uncontrolled hypertension, excessive alcohol intake or concomitant antiplatelet drugs) can be targeted for intervention to reduce potential risks.

\section{Intracranial bleeding}

The most severe bleeding complication is intracranial bleeding. In a systematic review of pivotal trials, DOACs were associated with a halving of intracranial haemorrhage compared with vitamin $\mathrm{K}$ antagonists. ${ }^{9}$ A similar reduction was noted in subsequent observational studies. ${ }^{14}$

If patients have an intracranial bleed on oral anticoagulants, emergency reversal is associated with better outcomes. Patients should be advised to go to hospital immediately if they develop strokelike symptoms. Reversal regimens are most readily available for those on warfarin and dabigatran.

\section{Gastrointestinal bleeding}

Gastrointestinal bleeding occurs twice as commonly as intracranial haemorrhage but has a lower mortality and lower long-term morbidity. DOACs are associated with a $25 \%$ increase in gastrointestinal bleeding events compared to vitamin K antagonists. Again, similar patterns were noted in the observational studies (although this might not be the case for all DOACs). ${ }^{6,9}$

\section{Renal impairment}

Oral anticoagulation for those in renal failure is complicated by two main factors. The DOACs are renally excreted and therefore need renal dose adjustment and are not recommended in severe renal failure. Dabigatran is recommended for use only when creatinine clearance is over $30 \mathrm{~mL} /$ minute. Rivaroxaban has recently been approved for use when creatinine clearance is over $15 \mathrm{~mL} /$ minute, with caution, using the $15 \mathrm{mg}$ daily dose. Apixaban should only be used when creatinine clearance is over $25 \mathrm{~mL} /$ minute. Warfarin is the only choice of oral anticoagulant for those with creatinine clearance less than $15 \mathrm{~mL} /$ minute or on dialysis. However, there are no reliable randomised controlled trial data that show warfarin is beneficial for stroke prevention in these patients (as renal failure is associated with an increased risk of bleeding). ${ }^{12}$

\section{Age and blood pressure}

Older people have a greater risk of stroke in atrial fibrillation (see $\mathrm{CHA}_{2} \mathrm{DS}_{2}$-VA score in the Table) and therefore still benefit from treatment despite the increased risk of bleeding. The Birmingham Atrial Fibrillation Treatment of the Aged Study (BAFTA) found that warfarin was superior to aspirin for 
stroke prevention in people aged 75 years and over (average age 81.5 years), with an annual absolute stroke prevention rate of $2 \%$. The extracranial bleed rate was similar in the warfarin and aspirin groups. ${ }^{15}$ This trial is particularly important as it demonstrated that, with good blood pressure control (85\% with a blood pressure below $160 \mathrm{mmHg}$ systolic), rates of intracranial haemorrhage were low $(<1 \%$ a year). The Australian national guidelines also mention the importance of blood pressure control as a method of reducing bleeding. ${ }^{12}$

\section{Falls}

Fall assessment is particularly important as falls are a common cause of death in older Australians - the death rate from falls is about a third of the death rate from stroke. ${ }^{16}$ The risk of dying following a fall is greatly increased for those on oral anticoagulation due to the increased risk of intracranial haemorrhage. This is mainly from subdural haemorrhage, but also includes subarachnoid haemorrhage and intracerebral haemorrhage. ${ }^{17-19}$ There are no reliable mortality data to know the size of this risk in Australia but data elsewhere suggest this could be in the hundreds per year. ${ }^{16-19}$

A holistic assessment such as a comprehensive geriatric review may help to weigh up the risks and benefits of oral anticoagulation for those at a high risk of falls. It is good practice to ask about any falls before starting anticoagulation, and at all subsequent reviews. Apixaban has been shown to be substantially better than aspirin for those with contraindications to warfarin, ${ }^{20}$ with additional benefits including dose adjustment by age, weight and renal function.

\section{Antiplatelet drugs}

Finally, clinicians need to be aware that combining oral anticoagulation with antiplatelet drugs always increases the risk of bleeding. However, the reduced risk of thrombotic events may justify this risk for short periods (e.g. after cardiac stenting). ${ }^{12}$ Clinicians need to ensure that an appropriate step down to a double or single antithrombotic regimen is carried out in a timely manner, depending on the circumstances. ${ }^{12}$

\section{Conclusion}

The introduction of the DOACs has been an advance in medicine, with their improved safety profile. However, there is evidence of considerable over- and under-treatment with oral anticoagulants in Australia. Strategies to improve compliance with guidelines need to be considered to improve health outcomes. «

Conflicts of interest: none declared

\section{REFERENCES}

1. Chugh SS, Havmoeller R, Narayanan K, Singh D, Rienstra M, Benjamin EJ, et al. Worldwide epidemiology of atrial fibrillation: a Global Burden of Disease 2010 Study. Circulation 2014;129:837-47. https://doi.org/10.1161/ CIRCULATIONAHA.113.005119

2. Leyden JM, Kleinig TJ, Newbury J, Castle S, Cranefield J, Anderson CS, et al. Adelaide stroke incidence study: declining stroke rates but many preventable cardioembolic strokes. Stroke 2013;44:1226-31. https://doi.org/10.1161/ STROKEAHA.113.675140

3. Newbury J, Kleinig T, Leyden J, Arima H, Castle S, Cranefield J, et al. Stroke epidemiology in an Australian rural cohort (search). Int J Stroke 2017;12:161-8. https://doi.org/10.1177/1747493016670174

4. Wilke T, Bauer S, Mueller S, Kohlmann T, Bauersachs R. Patient preferences for oral anticoagulation therapy in atrial fibrillation: a systematic literature review. Patient 2017;10:17-37. https://doi.org/10.1007/s40271-016-0185-9

5. Ferguson C, Hendriks J. Partnering with patients in shared decision-making for stroke prevention in atrial fibrillation. Eur J Cardiovasc Nurs 2017;16:178-80. https://doi.org/ 10.1177/1474515116685193

6. Proietti M, Romanazzi I, Romiti GF, Farcomeni A, Lip GY Real-world use of apixaban for stroke prevention in atrial fibrillation. Stroke 2018;49:98-106. https://doi.org/10.1161/ STROKEAHA.117.018395

7. Lip GY, Pan X, Kamble S, Kawabata H, Mardekian J, Masseria C, et al. Discontinuation risk comparison among 'real-world' newly anticoagulated atrial fibrillation patients: apixaban, warfarin, dabigatran, or rivaroxaban [Electronic Resource]. PLoS One 2018;13:e0195950. https://doi.org/ 10.1371/journal.pone.0195950

8. Lowres N, Giskes K, Hespe C, Freedman B. Reducing stroke risk in atrial fibrillation: adherence to guidelines has improved, but patient persistence with anticoagulant therapy remains suboptimal. Korean Circ J 2019;49:883-907. https://doi.org/10.4070/kcj.2019.0234
9. Ruff CT, Giugliano RP, Braunwald E, Hoffman EB, Deenadayalu N, Ezekowitz MD, et al. Comparison of the efficacy and safety of new oral anticoagulants with warfarin in patients with atrial fibrillation: a meta-analysis of randomised trials. Lancet 2014;383:955-62. https://doi.org/10.1016/S0140-6736(13)62343-0

10. Drug Utilisation Sub-Committee (DUSC). Novel oral anticoagulants: predicted vs actual analysis. Canberra: The Pharmaceutical Benefits Scheme, Department of Health; 2016. https://www.pbs.gov.au/pbs/industry/listing/ participants/public-release-docs/2016-06/noacs-nonvalvular-atrial-fibrillation-june-2016 [cited 2021 Mar 1]

11. Wong CX, Lee SW, Gan SW, Mahajan R, Rangnekar G, Pathak RK, et al. Underuse and overuse of anticoagulation for atrial fibrillation: a study in Indigenous and nonIndigenous Australians. Int J Cardiol 2015;191:20-4 https://doi.org/10.1016/j.ijcard.2015.03.064

12. Brieger D, Amerena J, Attia J, Bajorek B, Chan KH, Connell C, et al.; NHFA CSANZ Atrial Fibrillation Guideline Working Group. National Heart Foundation of Australia and the Cardiac Society of Australia and New Zealand: Australian clinical guidelines for the diagnosis and management of atrial fibrillation 2018. Heart Lung Circ 2018;27:1209-66. https://doi.org/10.1016/j.hlc.2018.06.1043

13. Stroke Foundation. InformMe. Clinical guidelines for stroke management [Living guidelines]. https://informme.org.au/ Guidelines/Living-guidelines-for-stroke-management [cited 2021 Mar 1]

14. Ntaios G, Papavasileiou V, Makaritsis K, Vemmos K, Michel P, Lip GY. Real-world setting comparison of nonvitamin-k antagonist oral anticoagulants versus vitamin-k antagonists for stroke prevention in atrial fibrillation. A systematic review and meta-analysis. Stroke 2017:48:2494-503. https://doi.org/ 10.1161/STROKEAHA.117.017549 
15. Mant J, Hobbs FD, Fletcher K, Roalfe A, Fitzmaurice D, Lip GY, et al.; BAFTA investigators; Midland Research Practices Network (MidReC). Warfarin versus aspirin for stroke prevention in an elderly community population with atrial fibrillation (the Birmingham Atrial Fibrillation Treatment of the Aged Study, BAFTA): a randomised controlled trial. Lancet 2007;370:493-503. https://doi.org/ 10.1016/S0140-6736(07)61233-1

16. Australian Bureau of Statistics. Causes of death, Australia, 2019. www.abs.gov.au/statistics/health/causes-death/ causes-death-australia/2019 [cited 2021 Mar 1]

17. Inui TS, Parina R, Chang DC, Inui TS, Coimbra R. Mortality after ground-level fall in the elderly patient taking oral anticoagulation for atrial fibrillation/flutter: a long-term analysis of risk versus benefit. J Traum Acute Car Surg 2014;76:642-49; discussion 649-50.

\section{FURTHER READING}

McCallum CJ, Raja DC, Pathak RK. Atrial fibrillation: an update on management. Aust Prescr 2019;42:186-91. https://doi.org/ 10.18773/austprescr.2019.067
18. Chisholm KM, Harruff RC. Elderly deaths due to ground-level falls. Am J Forensic Med Pathol 2010;31:350-4. https://doi.org/10.1097/PAF.0b013e3181f69c87

19. Boltz MM, Podany AB, Hollenbeak CS, Armen SB. Injuries and outcomes associated with traumatic falls in the elderly population on oral anticoagulant therapy. Injury 2015:46:1765-71. https://doi.org/10.1016/j.injury.2015.06.013

20. Connolly SJ, Eikelboom J, Joyner C, Diener HC, Hart R, Golitsyn S, et al.; AVERROES Steering Committee and Investigators. Apixaban in patients with atrial fibrillation N Engl J Med 2011;364:806-17. https://doi.org/10.1056/ NEJMoa1007432

Stevens H, Tran H, Gibbs H. Venous thromboembolism: current management. Aust Prescr 2019;42:123-6. https://doi.org/ 10.18773/austprescr.2019.039 